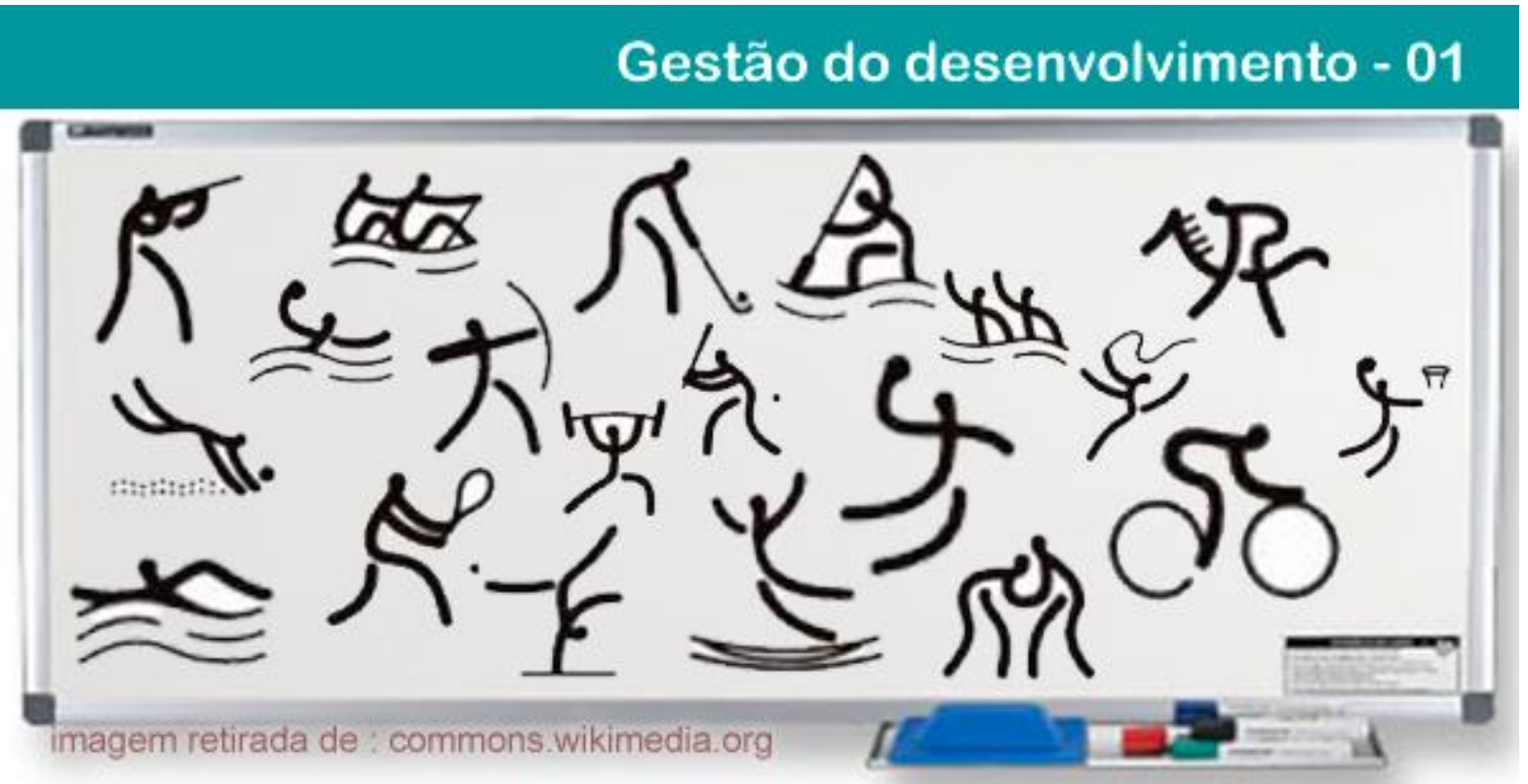

\title{
O LEGADO DE CIÊNCIA, TECNOLOGIA \& INOVAÇÃO (C, T \& I) DOS JOGOS ESPORTIVOS BRASILEIROS: UM RELATO BASEADO NA INFRAESTRUTURA DAS UNIVERSIDADES EMPREENDEDORAS
}

Branca Regina Cantisano dos Santos e Silva

Graduação em Engenharia Civil pela Universidade do Estado do Rio de Janeiro - UERJ (1977). Mestrado em Engenharia Civil pela Universidade Federal do Rio de Janeiro - UFRJ/COPPE (1988). Doutorado sanduíche pela State University of New York at Purchase - SUNY (1998) e doutorado em Engenharia de Produção pela Universidade Federal do Rio de Janeiro - UFRJ/COPPE (1999). Professora adjunta da UERJ, pesquisadora do programa Prociência e líder dos grupos de pesquisa Inovação e Sociedade e Inovação na Gestão Pública, implantou o Laboratório de Inovação e Empreendedorismo e vem implantando o Programa de Pré-incubação, Incubação e Pós-incubação da Rede de Incubadoras de Empresas da UERJ, ambos por meio de fomento da Fundação Carlos Chagas Filho de Amparo à Pesquisa do Estado do Rio de Janeiro - FAPERJ. E-mail: brancaterra@gmail.com.

\section{Lamartine Pereira da Costa}

Graduação em Ciências Navais pela Escola Naval (1958). Licenciatura em Educação Física pela EsEFEx (1963). Especialização Ergonomia pela FGV-RJ (1971). Doutorado em Filosofia pela Universidade Gama Filho-UGF (1989) e Livre Docente em Gestão do Esporte pela UERJ (1988). Pesquisador visitante da UERJ, Professor Visitante na University of East London-UK e Membro do Conselho Consultivo da Russian International Olympic University.E-mail: dacosta8@terra.com.br.

Leonardo Lehnemann Agostinho Martins

Formado em Administração com ênfase em Finanças na Universidade do Estado do Rio de Janeiro. Mestrado em Ciências Contábeis pela Universidade do Estado do Rio de Janeiro. E-mail: lehneman@ gmail.com.

\section{Marilda Sant'Anna Maciel}

Graduada em Ciências Contábeis pela Universidade Federal do Rio de Janeiro (2010). Mestranda em Ciências Contábeis pela Universidade do Estado do Rio de Janeiro. Analista de Planejamento e Orçamento - Secretaria de Estado de Planejamento e Gestão - Rio de Janeiro.E-mail: santannamaciel@gmail.com.

Mariza Costa Almeida

\section{POLÊM!CA $\mid$ LABORE (}

Polêmica - Revista Eletrônica da Uerj - Rua São Francisco Xavier, 524, $1^{\circ}$ andar bloco D, sl.1001 • Tels.: +55 21 2334-4088 / 4087 • http://www.e-publicacoes.uerj.br/index.php/polemica/index http://www.labore.uerj.br • laboreuerj@yahoo.com.br 
Graduação em Engenharia Agronômica pela Universidade Federal do Ceará (1982). Mestrado em Desenvolvimento, Agricultura e Sociedade pela Universidade Federal Rural do Rio de Janeiro (1997). Doutorado em Engenharia de Produção pela Universidade Federal do Rio de Janeiro (2004). Pós-doutorado no Georgia Institute of Technology, School of Public Policy. Professora Adjunta da Universidade Federal do Estado do Rio de Janeiro (UNIRIO), do Curso de Mestrado em Biblioteconomia e no Curso de Graduação em Engenharia de Produção. E-mail: almeida.mariza@globo.com.

Resumo: O objetivo desse trabalho é relatar o cenário brasileiro de fomento à inovação no esporte, observando o contexto dos jogos esportivos realizados no Brasil desde 2007, o que induziu a uma proposta de legado de C, T \& I, em função da infraestrutura de universidades empreendedoras, no país. O método usado nesta pesquisa constou de análise teórica e documental, além de entrevista com especialista na área de legados de eventos esportivos. O resultado mostrou um legado de C,T \& I devido ao apoio científico e tecnológico, que incentivou a inovação nas empresas, além de demonstrar que o país estava se preparando para os eventos esportivos que ocorreram desde 2007, os quais tiveram significativa participação das universidades empreendedoras como uma fonte de conhecimento de novos produtos e serviços, criando start-ups com o apoio do governo. A configuração da hélice tríplice no desenvolvimento de inovações no esporte no Brasil destaca o importante papel da universidade empreendedora na construção do legado de C, T \& I dos jogos esportivos que ocorreram no Brasil, e em especial dos Jogos Olímpicos Rio 2016.

Palavras-chave: Inovação no esporte. Jogos olímpicos. Universidade empreendedora. Legado de C,T\&I. Fomento. Start-ups.

\title{
THE LEGACY OF SCIENCE, TECHNOLOGY \& INNOVATION (C, T \& I) OF BRAZILIAN SPORTS GAMES: A REPORT BASED ON THE INFRASTRUCTURE OF ENTREPRENEURSHIP UNIVERSITIES
}

\begin{abstract}
The aim of this study is to report the Brazilian scenario of supporting sport innovation, observing the context of sports games held in Brazil since 2007, which led to a S, T \& I legacy proposal, depending on the infrastructure entrepreneurial universities in the country. The method used in this research consisted of theoretical and documentary analysis, and interviews with expert in the field of sporting events legacies. The result showed a legacy of $\mathrm{S}, \mathrm{T} \& \mathrm{I}$, due to scientific and technological support, which encouraged innovation in enterprises, as well as demonstrating that the country was preparing for the sporting events that have occurred since 2007, which had significant participation of entrepreneurial universities as a source of knowledge of new products and services, creating start-ups, with government support. The configuration of the triple helix in the development of innovations in the sport in Brazil highlights the important role of entrepreneurial university in building the legacy of S, T \& I of sports games that took place in Brazil and especially the Rio 2016 Olympic Games.
\end{abstract}

Keywords: Sport innovation. Olympic games. Entrepreneurial university. S, T \& I legacy. Grants. Start-ups.

Os Jogos Olímpicos de 2016 aconteceram no Rio de Janeiro, Brasil, de 5 a 21 de agosto de 2016. Diversas atividades foram desenvolvidas em eventos paralelos aos Jogos, entre estes, o evento acadêmico intitulado "Debate Público sobre Inovações nos Legados dos Jogos Olímpicos" em 11 de agosto, na Universidade Santa Úrsula, no Rio de Janeiro.

Naquela época, os pesquisadores do projeto "Um Estudo do grau de inovação de Empresas de Base Tecnológica - EBTs Brasileiras, Incubadas, Spin-offs Acadêmicos", apoiado pelo Conselho Nacional de Desenvolvimento Científico e Tecnológico - CNPq, apresentaram os resultados preliminares da pesquisa, e dentre eles, uma nova compreensão teórica foi destacada, a qual estende o conceito de legado de megaeventos esportivos. É o

\section{POLÊM!CA $\mid$ LABORE (}

Polêmica - Revista Eletrônica da Uerj - Rua São Francisco Xavier, 524, $1^{\circ}$ andar bloco D, sl.1001 • Tels.: +55 21 2334-4088 / 4087 • http://www.e-publicacoes.uerj.br/index.php/polemica/index http://www.labore.uerj.br • laboreuerj@yahoo.com.br 
legado científico e tecnológico com foco na inovação (legado de C, T\&I), baseado em investimentos do governo e de setores privados em laboratórios, em infraestrutura e em pessoas, para a realização de pesquisa em inovação no esporte, resultando no desenvolvimento de novos produtos e/ou serviços e na criação de novas empresas na área esportiva.

O objetivo desse trabalho é relatar o cenário brasileiro de fomento à inovação no esporte, observando o contexto dos jogos esportivos realizados no Brasil desde 2007, o que induziu a uma proposta de legado de C, T \& I, em função da infraestrutura de universidades empreendedoras no país.

O método usado nesta pesquisa constou de análise teórica e documental, além de entrevista com especialista na área de legados de eventos esportivos.

Os grandes eventos desportivos são transdisciplinares e estão diretamente ligados a vários segmentos da economia, uma vez que suas atividades exigem uma variedade de produtos, que vão desde roupas a tecnologia médica e serviços de infraestrutura, e cabe à sociedade identificar e tirar proveito das oportunidades oferecidas pelo setor. Tendo em vista que o setor de produção de esportes é «transversal», já que abrange uma variedade de diferentes áreas do conhecimento, a fim de atender às demandas específicas, seja na educação desportiva, no desporto de competição ou em atividades físicas voltadas para a promoção da saúde, a aprendizagem fornecida por universidades para a sociedade deve incluir ensino, pesquisa e extensão relacionadas com o esporte. Essas abordagens demonstram a interação indústria-governo-universidade como um meio de trazer grande impacto regional que, em termos práticos, pode muito bem ser considerado um legado empresarial efetivo de eventos desportivos (TERRA et al, 2011). Portanto, o legado dos eventos esportivos não se restringe apenas a resultados econômicos, mas também inclui infraestruturas culturais e desportivas, redes de mobilidade e melhoria ambiental, como Deslandes, DaCosta e Miragaya (2015) já demonstraram.

De acordo com Chappelet (2016), que deu uma palestra no debate acima mencionado, os impactos pós-jogos cobrem as áreas: 1) economia (atividade econômica, o turismo, empregos, impostos e investimentos estrangeiros); 2) sociopolíticas (notoriedade/imagem, despejos, voluntariado, protestos e de educação/participação) e 3) ambiental (construção, solo/água, energia, transporte e resíduos). Entre os impactos sócio-políticos, mostrou-se um

\section{POLÊM!CA $\mid$ LABORE}

Polêmica - Revista Eletrônica da Uerj - Rua São Francisco Xavier, 524, $1^{\circ}$ andar bloco D, sl.1001 • Tels.: +55 21 2334-4088/4087 • http://www.e-publicacoes.uerj.br/index.php/polemica/index http://www.labore.uerj.br • laboreuerj@yahoo.com.br 
forte impacto sobre o conhecimento dos organizadores, trabalhadores, voluntários e na percepção da sociedade em relação à organização dos jogos.

Além disso, Spilling (1996) apontou, com base na experiência anterior de países que já sediaram megaeventos internacionais de competição desportiva, que o legado para a cidadesede abrange também os impactos gerados pelo novo desempenho empresarial na região, o que pode afetar vários setores da economia.

Entretanto, o legado da C, T \& I ainda não havia sido considerado nesses trabalhos anteriores, apesar de mencionarem o legado do setor produtivo.

No Brasil, a perspectiva de hospedagem de vários eventos de esportes, como a Copa do Mundo de Futebol em 2014, os Jogos Mundiais Militares em 2011, a Copa da Confederação de Futebol em 2013 e os Jogos Olímpicos e Paralímpicos de 2016, bem como a experiência de sediar os Jogos Panamericanos e Parapan, em 2007, tem estimulado a discussão sobre a realização de tais "megaeventos" e seu legado para as cidades e regiões que os acolheram. Isso ampliou o debate na esfera acadêmica com reuniões científicas em curso e publicações sobre o tema a ser lançado de legado científico, tecnológico e de inovação (DACOSTA et al, 2008). Ao mesmo tempo, agências de governos que apoiam a pesquisa científica têm incluído, entre os seus editais, temas dedicados especificamente à inovação no esporte, exemplificando o entendimento de que o país poderia usar esta oportunidade para se tornar um produtor de soluções desportivas e não apenas um comprador.

Até o momento, há um ambiente favorável no Brasil ao estímulo da inovação tecnológica nas empresas, incluindo recursos financeiros não reembolsáveis, sujeitos à aprovação e aos regulamentos da Lei de Inovação (2004, 2005). Da mesma forma ocorreu o lançamento de programas econômicos do governo federal, tais como: o Plano para o Brasil Maior (2011 - 2015), que visa dar continuidade e expandir as medidas de política industrial que tinham sido introduzidas anteriormente; a PITCE - Política Industrial, Tecnológica e de Comércio Exterior (2003- 2007) e a PDP - Política para o Desenvolvimento da Produção (2008-2010) (TERRA et al, 2013).

Considerando que o Brasil tem um baixo grau de inovação em empresas (Pesquisa de Inovação -PINTEC, 2013) e as grandes empresas desportivas que desenvolvem pesquisa e desenvolvimento ( $\mathrm{P} \& \mathrm{D}$ ) são marcas internacionais, o que caracteriza o país como consumidor e não um produtor nas ferramentas inovadoras de desporto. Dessa forma, a

\section{POLÊM!CA $\mid$ LABORE}

Polêmica - Revista Eletrônica da Uerj - Rua São Francisco Xavier, 524, $1^{\circ}$ andar bloco D, sl.1001 • Tels.: +55 21 2334-4088/4087 • http://www.e-publicacoes.uerj.br/index.php/polemica/index http://www.labore.uerj.br • laboreuerj@yahoo.com.br 
iniciativa do governo para incentivar a inovação no esporte pode gerar um legado em $\mathrm{C}, \mathrm{T} \&$ I, num setor econômico até então inexistente.

Dentro deste contexto, a pesquisa citada no evento descrito anteriormente voltou-se para as empresas inovadoras situadas em incubadoras ligadas às universidades e para a identificação das interações realizadas entre universidades-indústrias-governo, com foco no desenvolvimento econômico e social e com base na inovação. Isso foi possível por causa da existência de incubadoras ligadas às universidades e institutos de pesquisa.

$\mathrm{O}$ resultado desse trabalho mostrou um legado de $\mathrm{C}, \mathrm{T} \& \mathrm{I}$ devido ao apoio científico e tecnológico, que incentivou a inovação nas empresas, além de demonstrar que o país estava se preparando para os eventos esportivos que ocorreram desde 2007, os quais tiveram significativa participação das universidades empreendedoras como uma fonte de conhecimento de novos produtos e serviços, criando start-ups com o apoio do governo.

Esta identificação de interações realizadas entre universidade-indústria-governo, focadas no desenvolvimento baseado na inovação, caracteriza a hélice tripla do desenvolvimento social e econômico das regiões (ETZKOWITZ e LEYDESDORF, 1995), bem como da tripla hélice de inovação nos esportes no Brasil, no caso particular em pauta.

Durante a pesquisa citada, os autores do projeto identificaram que no período de 2010 a 2014, foram aprovados 148 projetos de pesquisa e desenvolvimento de inovação nos esportes apresentados por universidades, institutos de pesquisa e empresas, totalizando oito pedidos de propostas (Programa de Apoio ao Desenvolvimento de Inovação em Esporte no Estado do Rio de Janeiro da Fundação Carlos Chagas Filho de Amparo à Pesquisa do Estado do Rio de Janeiro - FAPERJ, em 2010, 2012, 2013 e 2014; Seleção Pública do Ministério do Esporte - ME/CNPQ número 91/2013 - Desporto, Lazer e saúde - Projetos de cooperação em pesquisa científica, tecnologia e inovação, orientada para o desenvolvimento do desporto nas suas diferentes dimensões pelo CNPq/ME, em 2013; Seleção Pública 01/2012 - Ministério da Ciência, Tecnologia e Inovação - MCTI ${ }^{1} /$ Financiadora de Estudos e Projetos - FINEP/Fundo Nacional de Desenvolvimento Científico e Tecnológico - FNDCT - Inovador de Tecnologia Assistiva produtos treinamento e prática Esportes Paraolímpicos (subvenção econômica) pela FINEP em 2012; $26^{\circ}$ Prêmio Jovem Cientista do CNPq/Fundação para a Pesquisa do Estado de São Paulo - FAPESP/Fundação Roberto Marinho, Gerdau e General Electric - GE (MARTINS et al, 2016)), como mostra a

Tabela -1 a seguir:

\footnotetext{
${ }^{1}$ Desde 13/05/2016, o MCTI passou a se chamar Ministério da Ciência, Tecnologia, Inovação e Comunicações (MCTIC), conforme Portal Brasil (2016).
}

\section{POLÊM!CA $\mid$ LABORE}

Polêmica - Revista Eletrônica da Uerj - Rua São Francisco Xavier, 524, $1^{\circ}$ andar bloco D, sl.1001 • Tels.: +55 21 2334-4088/4087 • http://www.e-publicacoes.uerj.br/index.php/polemica/index http://www.labore.uerj.br • laboreuerj@yahoo.com.br 
Tabela - 1: Editais para inovação no esporte, empresas contempladas e valor investido por eles

\begin{tabular}{|c|c|c|c|c|c|c|c|c|c|c|c|c|c|c|}
\hline \multirow[b]{2}{*}{ Agência } & \multirow[b]{2}{*}{ Abrangência } & \multirow[b]{2}{*}{ Nome da Chamada } & \multicolumn{2}{|c|}{2014} & \multicolumn{2}{|c|}{2013} & \multicolumn{2}{|c|}{2012} & \multicolumn{2}{|c|}{2011} & \multicolumn{2}{|c|}{2010} & \multicolumn{2}{|c|}{ Valor investido por tipo de edital } \\
\hline & & & $\mathrm{E}$ & $\mathrm{C}$ & $\mathrm{E}$ & $\mathrm{C}$ & $\mathrm{E}$ & $\mathrm{C}$ & $\mathrm{E}$ & $\mathrm{C}$ & $\mathrm{E}$ & $\mathrm{C}$ & $\mathrm{R} \$$ & $\begin{array}{c}\text { US\$ (Cotação } \\
\text { do dólar em } \\
\text { 9/9/16: } \\
3,2632^{2} \text { ) }\end{array}$ \\
\hline $\begin{array}{l}\text { Fundação Carlos } \\
\text { Chagas Filho de } \\
\text { Amparo à Pesquisa } \\
\text { do Estado do Rio } \\
\text { de Janeiro - } \\
\text { FAPERJ }\end{array}$ & $\begin{array}{l}\text { Regional } \\
\text { (Rio de } \\
\text { Janeiro) }\end{array}$ & $\begin{array}{c}\text { PROGRAMA APOIO } \\
\text { AO } \\
\text { DESENVOLVIMENTO } \\
\text { DE INOVAÇÕES NO } \\
\text { ESPORTE NO } \\
\text { ESTADO DO RIO DE } \\
\text { JANEIRO }\end{array}$ & 1 & 16 & 1 & 16 & 1 & 23 & & & 1 & 16 & $10.000 .000,00$ & $3.110 .710,18$ \\
\hline $\begin{array}{c}\text { Conselho Nacional } \\
\text { de } \\
\text { Desenvolvimento } \\
\text { Científico e } \\
\text { Tecnológico - } \\
\text { CNPq/Ministério } \\
\text { do Esporte - ME }\end{array}$ & Nacional & $\begin{array}{c}\text { Seleção pública } \\
\text { ME/CNPQ número } \\
\text { 91/2013 - Esporte, } \\
\text { Lazer e Saúde - Projetos } \\
\text { de pesquisa científica, } \\
\text { tecnológica e de } \\
\text { inovação, voltados para } \\
\text { o desenvolvimento do } \\
\text { Esporte em suas } \\
\text { diferentes dimensões. }\end{array}$ & & & 1 & 65 & & & & & & & $18.000 .000,00$ & $5.599 .278,32$ \\
\hline
\end{tabular}

\footnotetext{
${ }^{2}$ Banco Central do Brasil. Taxas de Câmbio. 2016. Disponível em: <http://www4.bcb.gov.br/pec/taxas/port/ptaxnpesq.asp?id=txcotacao>. Acesso em: 09 ago. 2016.
}

\section{POLÊM!CA $\mid$ LABORE}

Polêmica - Revista Eletrônica da Uerj - Rua São Francisco Xavier, 524, $1^{\circ}$ andar

bloco D, sl.1001 • Tels.: +55 21 2334-4088 / 4087 • http://www.e-publicacoes.uerj.br/index.php/polemica/index

http://www.labore.uerj.br • laboreuerj@yahoo.com.br 


\begin{tabular}{|c|c|c|c|c|c|c|c|c|c|c|}
\hline Agência & Abrangência & Nome da Chamada & 2014 & 2013 & \multicolumn{2}{|c|}{2012} & 2011 & 2010 & \multicolumn{2}{|c|}{ Valor investido por tipo de edital } \\
\hline $\begin{array}{c}\text { Financiadora de } \\
\text { Estudos e Projetos } \\
\text { - FINEP }\end{array}$ & Nacional & $\begin{array}{c}\text { Seleção Publica 01/2012 } \\
- \\
\text { MCTI/FINEP/FNDCT- } \\
\text { Subvenção Econômica à } \\
\text { Inovação - Tecnologia } \\
\text { Assistiva Produtos } \\
\text { Inovadores para } \\
\text { Treinamentos e Pratica } \\
\text { de Esportes } \\
\text { Paralímpicos } \\
\text { (Subvenção Econômica) }\end{array}$ & & & 1 & 2 & & & 20.000.000,00 & $6.221 .420,35$ \\
\hline $\begin{array}{l}\text { CNPq/Fundação de } \\
\text { Amparo à Pesquisa } \\
\text { do Estado de São } \\
\text { Paulo - } \\
\text { FAPESP/Fundação } \\
\text { Roberto Marinho, } \\
\text { Gerdau e GE. }\end{array}$ & $\begin{array}{c}\text { Regional } \\
\text { (São Paulo) }\end{array}$ & $\begin{array}{l}26^{\circ} \text { Prêmio Jovem } \\
\text { Cientista }\end{array}$ & & & 1 & 9 & & & $600.000,00$ & $186.642,61$ \\
\hline \multicolumn{9}{|c|}{ TOTAIS = 7 editais (E) e 147 grupos de pesquisa ou empresas contempladas (C) } & $48.600 .000,00$ & 15.118.051,46 \\
\hline
\end{tabular}

Fonte: Martins et al (2016). Adaptado de Fundação de Amparo à Pesquisa do Estado do Rio de Janeiro (FAPERJ) (2010, 2012, 2013, e 2014), Financiadora de Estudos e

Projetos (FINEP) (2012), Conselho Nacional de Desenvolvimento Científico e Tecnológico (CNPq) (2013) e Portal Brasil (2014).

\section{POLÊM!CA $\mid$ LABORE}

Polêmica - Revista Eletrônica da Uerj - Rua São Francisco Xavier, 524, $1^{\circ}$ andar

bloco D, sl.1001 • Tels.: +55 21 2334-4088 / 4087 • http://www.e-publicacoes.uerj.br/index.php/polemica/index

http://www.labore.uerj.br • laboreuerj@yahoo.com.br 
Também foi realizada uma extensa pesquisa em 430 incubadoras brasileiras, de todas as regiões do país, em busca de spin-offs $^{3}$ incubadas/start-ups ${ }^{4}$ que foram desenvolvendo produtos e/ou serviços na área de inovação de esportes. Verificou-se que 19 incubadoras abrigaram 22 empresas com produtos e serviços relacionados com o campo de esportes, localizadas em sete diferentes estados, como mostra a Figura $\mathbf{- 1}$ a seguir:

Figura-1: Localização das empresas pesquisadas nos estados brasileiros.

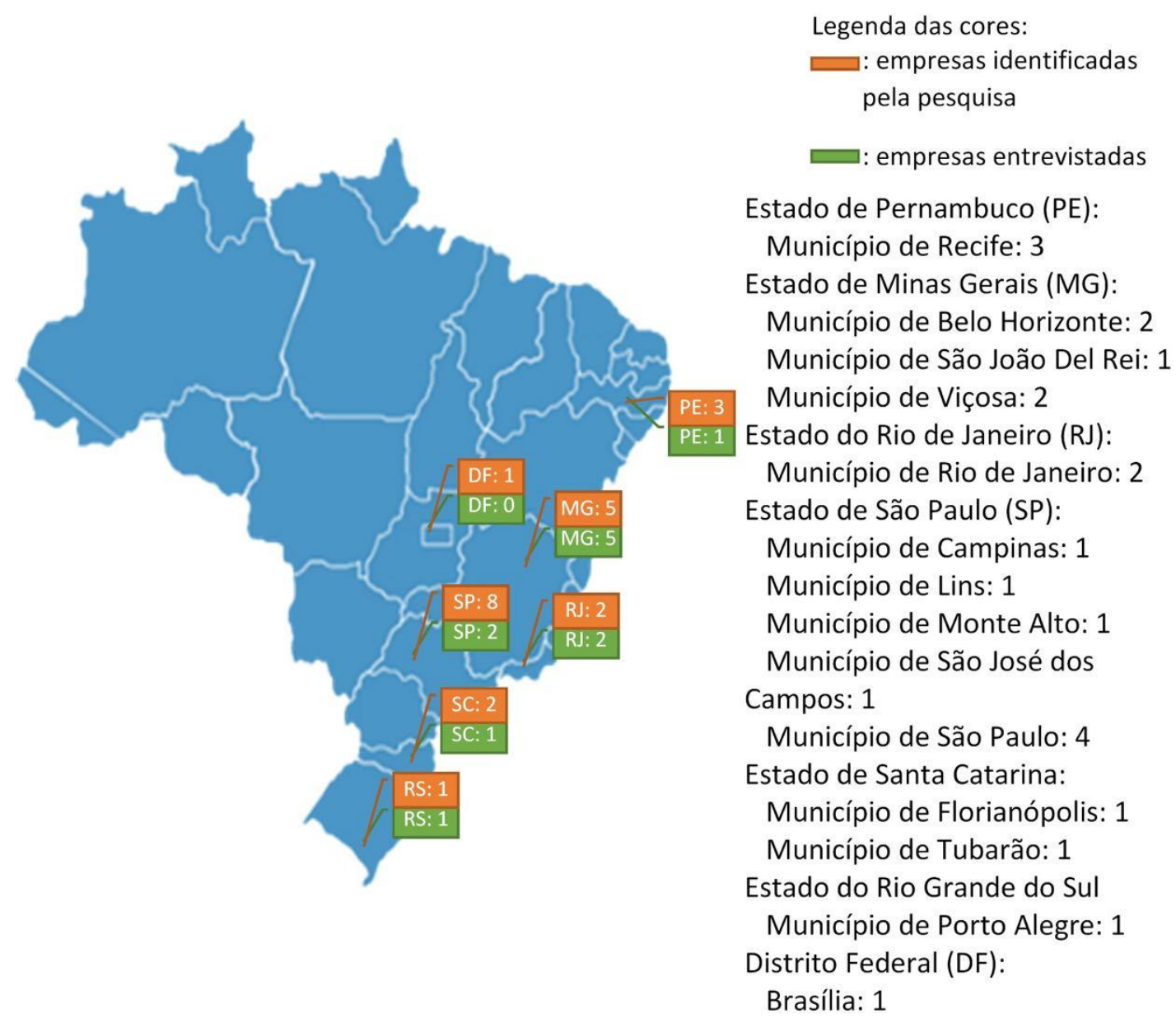

Fonte: Medeiros et al, 2016.

\footnotetext{
${ }^{3}$ Grandi e Grimaldi (2005) definem as spin-offs como uma nova empresa criada por um grupo de empregados de uma empresa existente, onde estes saem desta empresa para explorar a propriedade intelectual criada dentro dela. Normalmente a empresa da qual os empregados saíram também se torna sócia da nova empresa. E também pessoas de fora da empresa original podem vir a formar a nova empresa junto com os empregados da empresa original.

${ }^{4}$ São empresas "[...] em fase embrionária, geralmente no processo de implementação e organização de suas operações. Pode não ter ainda iniciado a comercialização em massa de seus produtos, mas já está a funcionar ou, pelo menos, em processo final de instalação" (TABORDA, 2006).
}

\section{POLÊM!CA $\mid$ LABORE}

Polêmica - Revista Eletrônica da Uerj - Rua São Francisco Xavier, 524, $1^{\circ}$ andar

bloco D, sl.1001 • Tels.: +55 21 2334-4088/4087 • http://www.e-publicacoes.uerj.br/index.php/polemica/index http://www.labore.uerj.br • laboreuerj@yahoo.com.br 
$\mathrm{Na}$ primeira fase do estudo, os pesquisadores reuniram 22 empresas incubadas em que a fonte de conhecimento para o desenvolvimento da inovação eram projetos de pesquisa, teses, dissertações, trabalhos finais de graduação e pesquisa científica. Na segunda etapa da pesquisa, ainda em curso, o grau de inovação dessas empresas foi identificado.

A Figura -2, a seguir, mostra a configuração da tripla hélice destacando o papel de cada instituição hélice a partir das informações coletadas durante a pesquisa empírica com a identificação de empresas em incubadoras.

Figura-2: Hélice Tríplice.

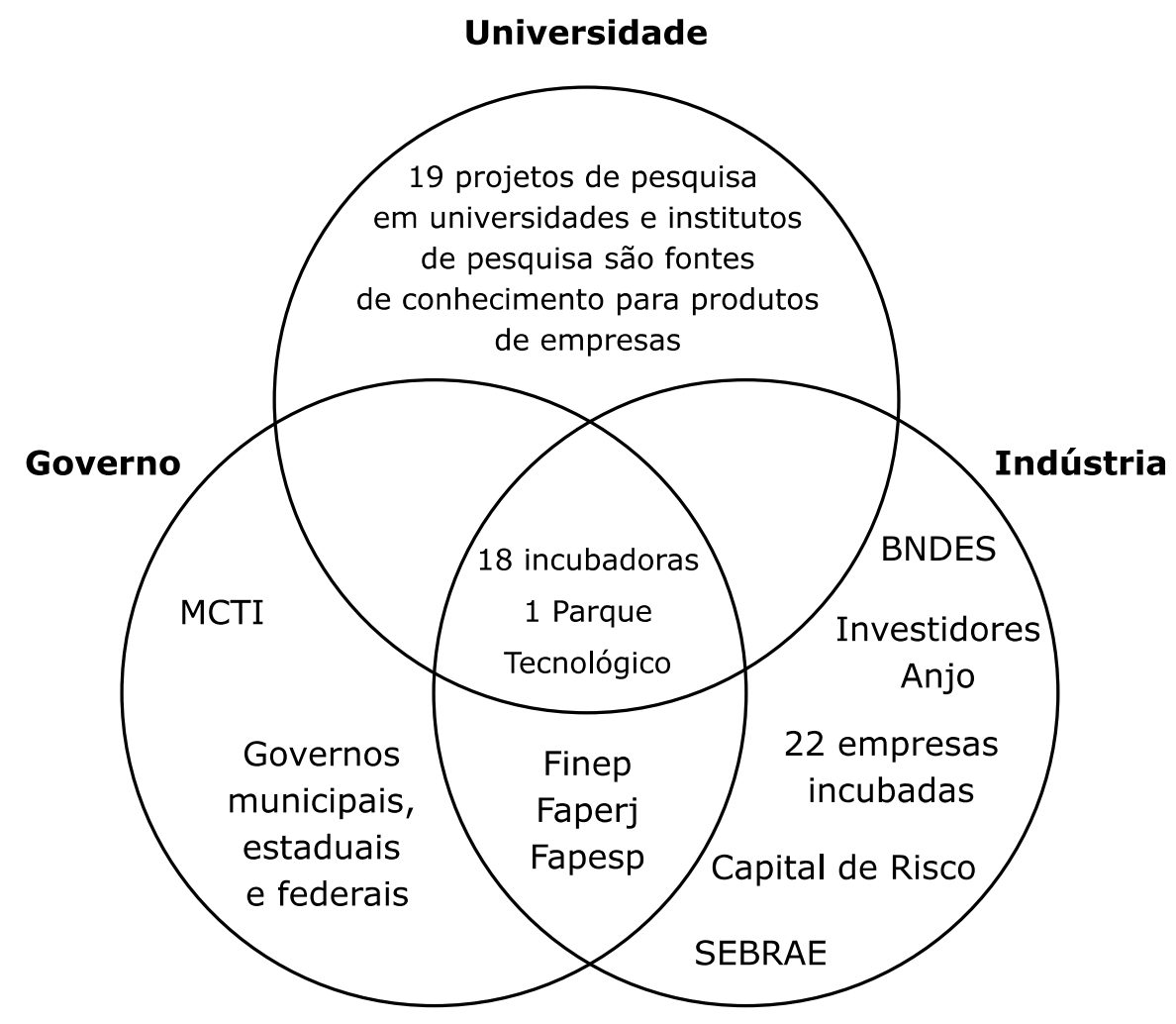

Fonte: Os Autores.

Como conclusão, observa-se que a configuração da hélice tríplice no desenvolvimento de inovações no esporte no Brasil destaca o importante papel da universidade empreendedora na construção do legado de C, T \& I dos jogos esportivos, principalmente sobre os que ocorreram no Brasil e em especial dos Jogos Olímpicos Rio 2016.

Como pesquisa futura na área de inovação no esporte, sugere-se a criação de indicadores para definir o impacto do legado, expressando as características e nível das

\section{POLÊM!CA $\mid$ LABORE}

Polêmica - Revista Eletrônica da Uerj - Rua São Francisco Xavier, 524, $1^{\circ}$ andar bloco D, sl.1001 • Tels.: +55 21 2334-4088/4087 • http://www.e-publicacoes.uerj.br/index.php/polemica/index http://www.labore.uerj.br • laboreuerj@yahoo.com.br 
realizações inovadoras no período de preparação, realização e pós-realização dos megaeventos esportivos.

\section{Referências}

BRASIL. Decreto lei n. 5.563, de 11 de outubro de 2005. Regulamenta a Lei no 10.973, de 2 de dezembro de 2004, que dispõe sobre incentivos à inovação e à pesquisa científica e tecnológica no ambiente produtivo, e dá outras providências. Diário Oficial [da] República Federativa do Brasil, Brasília, DF, 13 out. 2005.

Disponível em: <http://www.planalto.gov.br/ccivil_03/_ato2004-2006/2005/decreto/d5563.htm〉. Acesso em: 09 ago. 2016.

BRASIL. Lei n. 10.973, de 2 de dezembro de 2004. Dispõe sobre incentivos à inovação e à pesquisa científica e tecnológica no ambiente produtivo e dá outras providências. Diário Oficial [da] República Federativa do Brasil, Brasília, DF, 16 maio 2005. Disponível em: <http://www.planalto.gov.br/ccivil_03/_ato2004-

2006/2004/lei//10.973.htm>. Acesso em: 09 ago. 2016.

CHAPPELET, J-L. (2016) Apresentação "Beyond Legacy: From pre-Games Impact to Post-Games Heritage. Universidade Santa Úrsula, Rio de Janeiro, RJ, Brasil em 11 de agosto de 2016.

CONSELHO NACIONAL DE DESENVOLVIMENTO CIENTÍFICO E TECNOLÓGICO (CNPQ). Chamadas Públicas. CNPq. 2013. Disponível em: <http://cnpq.br/chamadas-

publicas?p_p_id=resultadosportlet_WAR_resultadoscnpqportlet_INSTANCE_0ZaM\&filtro=resultados\&detalha $=$ chamadaDivulgada\&idDivulgacao=4321>. Acesso em: 09 ago. 2016.

DACOSTA, L. P.; CORREA, D.; RIZZUT, E.; VILLANO, B. (eds.). Legados de Mega eventos esportivos. Brasília: Ministério dos Esportes, 2008.

DESLANDES, A.; DACOSTA, L. P.; MIRAGAYA, A. The Future of Sports Megaevents. Rio de Janeiro: Engenho e Arte, 2015.

ETZKOWITZ, Henry; LEYDESDORFF, Loet. The Triple Helix--University-industry-government relations: A laboratory for knowledge based economic development. EASST review, v. 14, n. 1, p. 14-19, 1995.

FINANCIADORA DE ESTUDOS E PROJETOS (FINEP). Seleção Pública MCTI/FINEP/FNDCT Subvenção Econômica à Inovação - 01/2012 - Tema: Tecnologia Assistiva. Finep. 2012. Disponível em: <http://www.finep.gov.br/chamadas-publicas/chamadapublica/509>. Acesso em: 09 ago. 2016.

FUNDAÇÃO DE AMPARO À PESQUISA DO ESTADO DO RIO DE JANEIRO (FAPERJ). Lista de editais lançados em 2010. FAPERJ. 2010. Disponível em: <http://www.faperj.br/?id=1610.3.2>. Acesso em: 09 ago. 2016.

FUNDAÇÃO DE AMPARO À PESQUISA DO ESTADO DO RIO DE JANEIRO (FAPERJ). Lista de Editais lançados em 2012. FAPERJ. 2012. Disponível em: <http://www.faperj.br/?id=2138.3.0>. Acesso em: 09 ago. 2016.

FUNDAÇÃO DE AMPARO À PESQUISA DO ESTADO DO RIO DE JANEIRO (FAPERJ). Lista de Editais lançados em 2013. FAPERJ. 2013. Disponível em: <http://www.faperj.br/?id=2456.3.4>. Acesso em: 09 ago. 2016.

FUNDAÇÃO DE AMPARO À PESQUISA DO ESTADO DO RIO DE JANEIRO (FAPERJ). Editais lançados em 2014. FAPERJ. 2014. Disponível em: <http://www.faperj.br/?id=3031.3.3〉. Acesso em: 09 ago. 2016.

\section{POLÊM!CA $\mid$ LABORE}

Polêmica - Revista Eletrônica da Uerj - Rua São Francisco Xavier, 524, $1^{\circ}$ andar bloco D, sl.1001 • Tels.: +55 21 2334-4088/4087 • http://www.e-publicacoes.uerj.br/index.php/polemica/index http://www.labore.uerj.br • laboreuerj@yahoo.com.br 
GRANDI, Alessandro; GRIMALDI, Rosa. Academics' organizational characteristics and the generation of successful business ideas. Journal of Business Venturing, v. 20, n. 6, p. 821-845, 2005. Disponível em: <http://www.sciencedirect.com/science/article/pii/S0883902604001004>. Acesso em: 28 jan. 2013.

MARTINS, L. L.; MACIEL, M. S. A.; ALMEIDA, M.; TERRA, B. R. C. dos S. e S. Tabela de Suporte Governamental à Inovação no Esporte de 2010 a 2016. 2016.

INSTITUTO BRASILEIRO DE GEOGRAFIA E ESTATÍSTICA (IBGE). Pesquisa Industrial de Inovação Tecnológica: PINTEC 2013. Brasília: Instituto Brasileiro de Geografia e Estatística, 2013.

PORTAL BRASIL. Divulgados os vencedores do 26$^{\circ}$ Prêmio Jovem Cientista. 2014. Disponível em: <http://www.brasil.gov.br/ciencia-e-tecnologia/2012/11/divulgados-os-vencedores-do-26o-premio-jovemcientista>. Acesso em: 09 ago. 2016.

PORTAL BRASIL. Para buscar eficiência, novo governo corta ministérios. 2016. Disponível em: <http://www.brasil.gov.br/governo/2016/05/para-buscar-eficiencia-novo-governo-corta-ministerios>. Acesso em: 09 ago. 2016.

SPILLING, O. R. The entrepreneurial system: On entrepreneurship in the context of a mega-event. Journal of Business Research, v. 36, n. 1, p. 91-103, 1996.

TABORDA, Ana. O que é uma start up? 2006. Disponível em:

<http://www.gesentrepreneur.com/pdf/o_que_e_uma_start_up.pdf > Acesso em: 13 set. 2016.

TERRA, B.; ALMEIDA, M.; BATISTA, L. A.; CAMPOS, S. R. C. A oportunidade de inovação no esporte é nossa! Polêm!ca, v. 10, p. 1-1, 2011.

TERRA, B.; BATISTA, L. A.; CAMPOS, S. R. C.; ALMEIDA, M. Interaction Among Universities, Government and Spin-off Firms in a Brazilian Context to Generate Sports Innovation. Journal of technology management \& innovation, v. 8, n. 2, p. 93-106, 2013.

Recebido em: 11/10/2016.

Aceito em: 18/03/2017.

\section{POLÊM!CA LABORË}

